\title{
Feline Erythroleukemia
}

National Cancer Institute

\section{Source}

National Cancer Institute. Feline Erythroleukemia. NCI Thesaurus. Code C134770.

Erythroleukemia that occurs in a cat. 